\title{
A Novel Method of Electric Scooter Torque Estimation Using the Space Vector Modulation Control
}

\author{
Chergui Hichama ${ }^{a}$ Abdelfatah Nasria1, Korhan Kayislib, \\ ${ }^{a}$ Laboratory of Smart Grids \& Renewable Energies (S.G.R.E), Faculty of Technology, Department of Electrical Engineering, \\ Tahri Mohamed University Bechar, B.P 417, 08000, Algeria \\ ${ }^{b}$ Department of Electric Electronics Engineering, Faculty of Engineering, Nisantasi University, 34310, Istanbul, Turkey
}

\begin{abstract}
In recent years, there are many studies have been conducted in the field of light electric vehicles, especially electric scooters. These are preferred in large urban areas that are crowded with cars and cause traffic congestion in the European and Asian continents. In this study, the three-wheel electric scooter contained two BLDC motors that drove the rear wheels and, each of these motors were controlled independently via an electronic differential. This paper aims to implement a Space Vector Modulation for the Direct Torque Control unit (SVM-DTC) of the BLDC wheel-motor of each driving wheel. The proposed system had been designed and simulated by using the MATLAB/SIMULINK environment. The performance of the overall system (scooter stability control system - energy storage system power quality, etc.) with using SVM-DTC control was compared with the classical Direct Torque Control (DTC) algorithm by using the same electric scooter model. The obtained results showed clearly the improvement made by the proposed control loop system at different stages, where it could reduce the THD of the stator current from $30.99 \%$ to $6.16 \%$, as well as it was able to achieve more than $0.2 \%$ of the charging state of the battery in 18 seconds only.
\end{abstract}

Keywords: Three-wheel scooter, electric vehicle, BLDCM, space vector modulation, direct torque control, electronic differential.

Article History: Received: $9^{\text {th }}$ Oct 2020; Revised: $3^{\text {rd }}$ Dec 2020; Accepted: $15^{\text {th }}$ January 2021; Available online: $20^{\text {th }}$ January 2021

How to Cite This Article: Chergui, H., Nasri, A., Kayisli, K. (2021), A Novel Method of Electric Scooter Torque Estimation Using the Space Vector Modulation Control. Int. Journal of Renewable Energy Development, 10(2), 355-364

https://doi.org/10.14710/ijred.2021.33403

\section{Introduction}

In the last decade, the world has witnessed a continuous advance in electric vehicle technologies, and many important types of research have been performed about this field. However, the realization problem of the electricity storage systems has not been solved with high density yet (Han et al. 2014; Marzougui et al. 2017). Currently, practical solutions are being generally used on hybrid electric cars. The preferred methods such as fuel cell and internal combustion engines lead to complexity and increase costs (Andreasen et al. 2008; Jensen et al. 2012).Due to these difficulties, electric vehicles have not met increased autonomy and light electric vehicles such as motorcycles and scooters are generally dedicated to large urban areas instead of electrical vehicles yet (Bertoluzzo et al. 2011; Jeong et al. 2019). In fact, the use of electric scooter has become very popular especially in large urban areas which have heavy traffic. Unfortunately, more acceleration was still required in the same area as the previous prototypes could not provide an equivalent speed. Electric scooters are widely used around the world, and also, they are called instant electrical counterparts (Pellegrino et al. 2009). Many types of electric scooters have been produced and sold in the market. One of the popular types is the 3 -Wheel Scooter (3-WSC), and it is preferred especially in crowded cities and city centers. Also, there are some 3 -WSCs that have been patented (Pizzi et al. 2012; Lovley et al. 2017).

Furthermore, some studies and researches about 3WSCs have been performed by researchers. In a study, the researchers tried to improve the drive performance of 3 WSC in large urban states. As a low-cost alternative, they prepared a prototype including two axial flux permanent magnet (AFPM) motors placed on the rear wheels and integrated linear hall effect position sensors (Caricchi et al. 2003). In another study, fuzzy logic control was preferred to control the speed of 3-WSC. There were two independent brushless direct current (BLDC) motors used with an electronic differential system (Hichem et al. 2019). In India, many types of researches were performed to obtain the electric consumptions of two-three-four wheels electric scooters and some suggestions were presented to reduce energy consumption (Saxena et al. 2014. For the energy management of 3-WSC light electric vehicles, multi-sources energy models, and rule-based feedback control algorithms were used in a study (Hannan et al. 2012). Additionally, a prototype design was obtained in another study with light vehicles. The 3D designs and the analysis for load calculation were performed with CATIA, and ANSYS programs, respectively (Harušinec et al.

\footnotetext{
${ }^{1}$ Corresponding author:nasriab1978@yahoo.fr,
} 
2019). In another paper, rigid body modelling of threewheel vehicles for determining the dynamic stability was explored practically (Sindha et al. 2015).

In this study, a control algorithm for better performance of a three-wheel electric scooter is proposed. The presented prototype contains an electronic differential, a Li-ion battery, dc-dc converter, inverters for the left-right wheels, gears and BLDC motor. This threewheel electric scooter contains two BLDC motors which drive the two rear wheels and each is controlled independently with the space vector modulation for direct torque control (SVM-DTC) unit with an electronic differential. The motors are fed using inverters powered by a lithium-ion battery block. The electronic differential provides automatic control for each wheel, ensuring the scooter stability when entering a curved road. Simulations of the studied prototype are performed by using the MATLAB/SIMULINK environment. Additionally, the classic six-step controller is also used to check and compare the performance of the suggested SVM-DTC.

\section{Electric scooter traction system elements}

Three opposite forces are working on the movement of the scooter. These are the rolling resistance force, aerodynamic, drag force and slope force which are illustrated in Fig.1 (Boumediene et al. 2020, Abdelfatah et al 2008, Abdelfatah et al 2011).

The rolling force $F_{t i r}$ :

$$
F_{t i r}=f_{r} \cdot m \cdot g
$$

The aerodynamic force $F_{a e r}$ :

$$
F_{a e r}=\frac{1}{2} \cdot \rho_{a} \cdot s \cdot c_{x} \cdot V_{L}^{2}
$$

The slope force $F_{s l}$ :

$$
F_{s l}=m \cdot g \cdot \sin \beta
$$

Total resistance forces $F_{r}$ :

$$
F_{r}=F_{t i r}+F_{a e r}+F_{s l}
$$

Where, $m$ is the scooter mass, $g$ is the gravity acceleration, sis the frontal surface area of the scooter, $\rho_{a}$ is the air density, $f_{r}$ is the rolling force constant and $c_{x}$ is the aerodynamic drag coefficient.

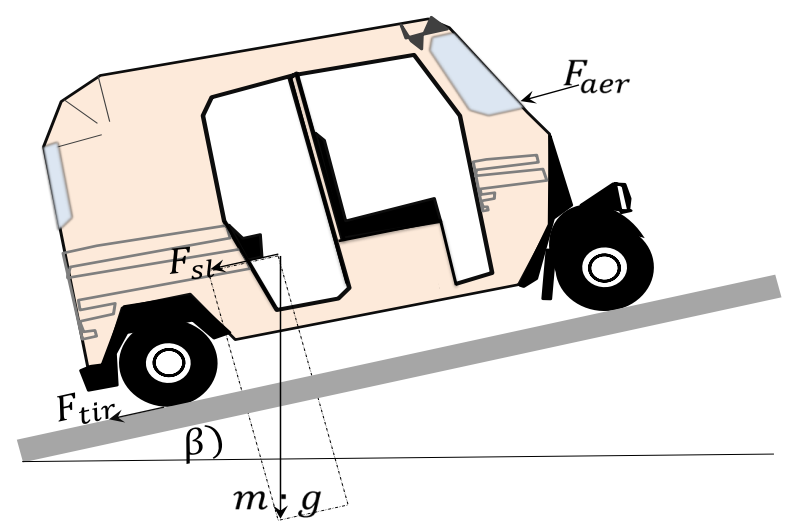

Fig. 1. The scooter acting forces during slope.

\subsection{The energy source of e-scooter}

The Li-ion battery is widely used particularly in light electric cars, electric motorcycles, and scooters because of its benefits, specifically the high density concerning the lightweight model. The lithium battery has both a charge and discharge status. The equations of these situations (discharge and charge) for the lithium battery are given in Eq. 5 and Eq. 6, respectively (Han et al. 2014, Nasri et al 2010, Nasri et al 2017).

For $i_{f}>0$ (Discharge model)

$f_{d i s}\left(i_{c}, i_{f}\right)=E_{0}-\frac{k \cdot Q_{M}}{Q_{M}+i_{c}} i_{f}-\frac{k \cdot Q_{M}}{Q_{M}-i_{c}} i_{c}+\alpha e^{-\beta \cdot i_{c}}$

For $i_{f}<0$ (Charge model)

$$
f_{\text {che }}\left(i_{c}, i_{f}\right)=E_{0}-\frac{k \cdot Q_{M}}{0.1 \cdot Q_{M}+i_{c}} i_{f}-\frac{k \cdot Q_{M}}{Q_{M}-i_{c}} i_{c}+\alpha e^{-\beta \cdot i_{c}}
$$

Where $E_{0}$ is constant voltage $(\mathrm{V}), k$ is steady constant (Ah), $i_{f}$ is low-frequency current dynamics (A), $i_{c}$ is extorted capacity (Ah), $Q_{M}$ is maximum battery capacity (Ah), ois exponential voltage (V), $\beta$ is the exponential capacity (Ah).

\subsection{DC-DC Buck-Boost Converter}

In electric scooters, dc-dc converter usage is a requirement, and boost or buck-boost converters are generally used. In this prototype, a buck-boost converter that supports an output voltage both higher and lower than the input voltage depends on duty-cycle is preferred (Hichem et al. 2019, Kommula et al 2019).

A proportional-integral controller (PI controller) is used to control the duty cycle and support a constant output voltage under load changes. The buck-boost converter circuit and its controller are illustrated in Fig. 2 .

\subsection{Brushless DC Motors}

BLDC Motors are widely preferred and used due to some important features such as the tiny size, the high torque density, efficiency with quiet operation, much suitable for steering wheel controls and low maintenance.

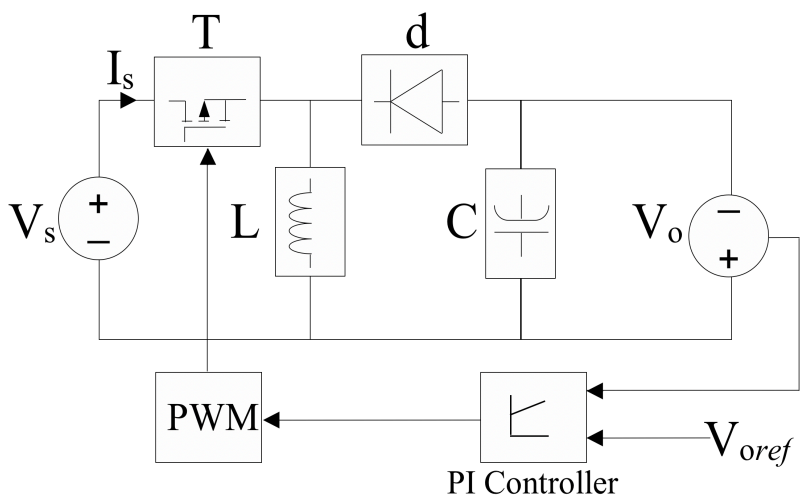

Fig. 2. A classical buck-boost converter circuit. 


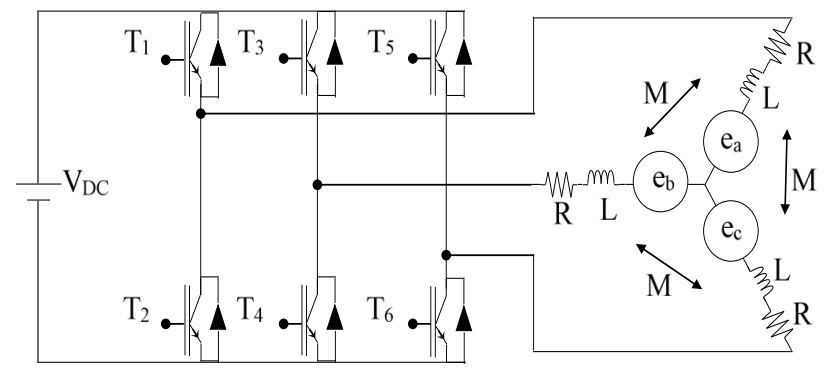

Fig. 3. Electric schema of BLDC Motor Drive System

The rotors of the BLDC motor are generally placed internally or sometimes externally. Both types are constructed with permanent magnets. The total number of magnetic parts and the number of motor poles are identical (Boumediene et al. 2020). The construction of the BLDC motor drive is illustrated in Fig. 3. The mathematical model of the three-phase BLDC motor is described by Eq. 7 as follows:

$\left[\begin{array}{l}v_{a} \\ v_{b} \\ v_{c}\end{array}\right]=\left[\begin{array}{ccc}R & 0 & 0 \\ 0 & R & 0 \\ 0 & 0 & R\end{array}\right]\left[\begin{array}{l}i_{a} \\ i_{b} \\ i_{c}\end{array}\right]+\frac{d}{d t}\left[\begin{array}{ccc}L-M & 0 & 0 \\ 0 & L-M & 0 \\ 0 & 0 & L-M\end{array}\right]\left[\begin{array}{c}i_{a} \\ i_{b} \\ i_{c}\end{array}\right]+\left[\begin{array}{c}e_{a} \\ e_{b} \\ e_{c}\end{array}\right]$

Where, $v_{a}, v_{b}, v_{c}$ and $i_{a}, i_{b}, i_{c}$ are three-phase voltages and currents $e_{a}, e_{b}, e_{c}$, are phase BEMF, $R$, and $L$ are the stator resistance and inductance, respectively, and is the mutual inductance. In Eq.8 and Eq.9, the electromagnetic and mechanical torque equations are given, respectively. In these equations, $T_{L}, j, \omega$, fare load torque, inertia, damping, and angular speed of the rotor respectively.

$$
T_{e}=\frac{i_{a} \cdot e_{a}+i_{b} \cdot e_{b}+i_{c} \cdot e_{c}}{\omega}
$$

$j \frac{d \omega}{d t}=T_{e}-f \cdot \omega-T_{L}$

\section{The design of a speed controller and Electronic Differential System (EDS)}

The BLDC motor is driven via an inverter and the speed is controlled by a closed-loop PI controller. Also, Space Vector Modulation (SVM) method is used for Direct Torque Control (DTC).

\subsection{Speed Controller for BLDCM}

The brushless direct current motor (BLDCM) is driven by an inverter supplied with DC voltage. The speed is controlled by a closed-loop depending on the PI regulator to obtain a reference electromagnetic torque. Figure 4 represents the diagram of the classical speed controllers that are applied to the BLDC motor. The reference current is obtained by multiplying the electromagnetic torque and the torque constant. Also, depending on the rotor position, the current control unit generates the three reference stator currents of the motor. Consequently, the inverter is controlled by comparison with the three actual currents and reference currents using the hysteresis current controller unit.

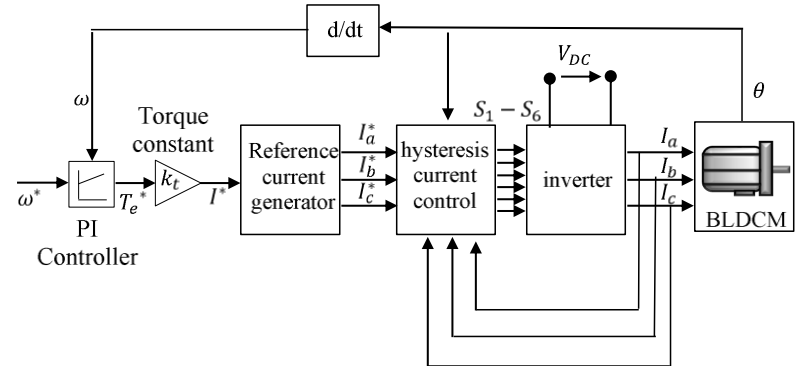

Fig. 4. General diagram of the classical speed controller applied to the BLDC motor

\subsection{Direct Torque Control Based Space Vector Modulation (SVM-DTC)}

In this control strategy, the flow link and the torque are calculated according to the reference of the two-phase stator (i.e. according to the framework $\alpha-\beta$ ), which uses the Clark transformation to transform three phases $a-b$ - $c$. The Clark transformation is presented with the following equation (Duesterhoeft et al. 1951):

$$
f_{\alpha \beta o}(t)=P \cdot f_{a b c}(t)=\frac{2}{3}\left[\begin{array}{ccc}
1 & -\frac{1}{2} & -\frac{1}{2} \\
0 & \frac{\sqrt{3}}{2} & -\frac{\sqrt{3}}{2} \\
\frac{1}{2} & \frac{1}{2} & \frac{1}{2}
\end{array}\right]\left[\begin{array}{l}
f_{a}(t) \\
f_{b}(t) \\
f_{c}(t)
\end{array}\right]
$$

The inverse transform is:

$$
f_{a b c}(t)=P^{-1} \cdot f_{\alpha \beta o}(t)=\frac{2}{3}\left[\begin{array}{ccc}
1 & 0 & 1 \\
-\frac{1}{2} & \frac{\sqrt{3}}{2} & 1 \\
-\frac{1}{2} & -\frac{\sqrt{3}}{2} & 1
\end{array}\right]\left[\begin{array}{l}
f_{\alpha}(t) \\
f_{\beta}(t) \\
f_{o}(t)
\end{array}\right]
$$

$f_{o}(t)$ is zero in the case of a balanced three-phase system, therefore the simplified form of Clarke's transformation is (Tahri et al. 2007):

$$
f_{\alpha \beta}(t)=\frac{2}{3}\left[\begin{array}{ccc}
1 & -\frac{1}{2} & -\frac{1}{2} \\
0 & \frac{\sqrt{3}}{2} & -\frac{\sqrt{3}}{2}
\end{array}\right]\left[\begin{array}{l}
f_{a}(t) \\
f_{b}(t) \\
f_{c}(t)
\end{array}\right]
$$

The inverse transform is:

$$
f_{a b c}(t)=\frac{3}{2}\left[\begin{array}{cc}
\frac{2}{3} & 0 \\
-\frac{1}{3} & \frac{\sqrt{3}}{3} \\
-\frac{1}{3} & -\frac{\sqrt{3}}{3}
\end{array}\right]\left[\begin{array}{l}
f_{\alpha} \\
f_{\beta}
\end{array}\right]
$$

In this method, a PI controller is used to control the speed and, two PI controllers are used instead of the hysteresis band (DTC technique without SVM) to control the torque and the amplitude of the flux.

The BLDC motor stator flux can be estimated by:

$$
\begin{aligned}
& \psi_{\alpha}=\int V_{\alpha}-R I_{\alpha} d t \\
& \psi_{\beta}=\int V_{\beta}-R I_{\beta} d t
\end{aligned}
$$




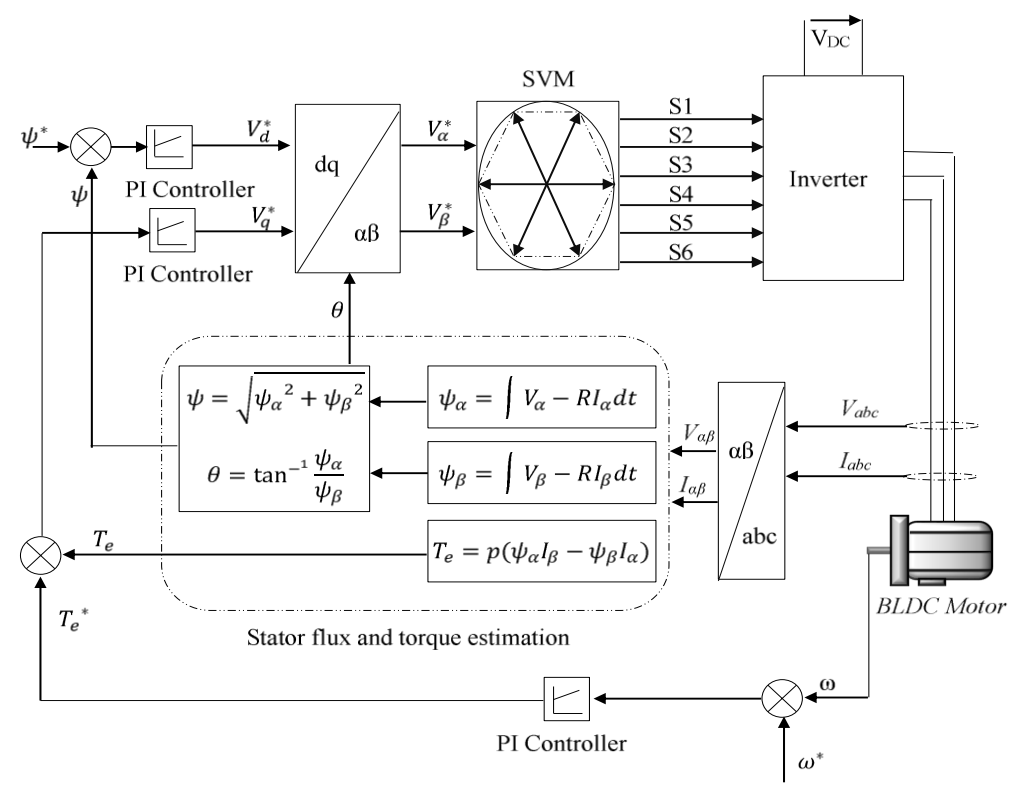

Fig. 5.Control diagram of the BLDCM using the SVM-DTC controller

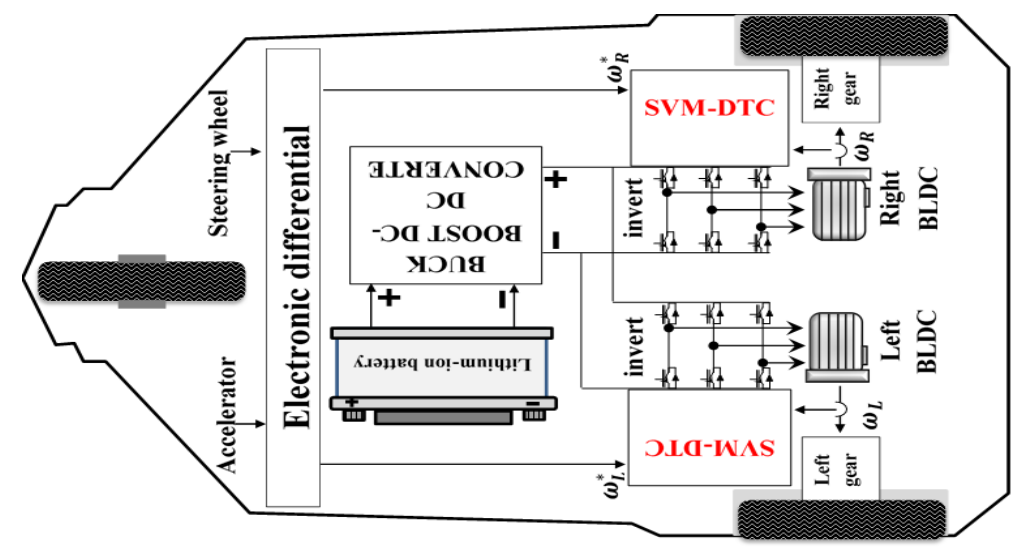

Fig. 6. The general diagram of the traction system of the three-wheel electric scooter

$$
\begin{aligned}
& \psi=\sqrt{\psi_{\alpha}^{2}+\psi_{\beta}^{2}} \\
& \theta=\tan ^{-1} \frac{\psi_{\alpha}}{\psi_{\beta}}
\end{aligned}
$$

The electromagnetic torque $T_{e}$ can be given as follow:

$$
T_{e}=p\left(\psi_{\alpha} I_{\beta}-\psi_{\beta} I_{\alpha}\right)
$$

The BLDCM with the application of the SVM-DTC controller is shown in Fig. 5. In Fig.6, the general diagram of the traction system of the scooter is presented with the application of the controller on the two BLDC motors.

\subsection{Electronic Differential System (EDS)}

On a straight road, the rear wheels get an equivalent speed and torque; however, the interior and exterior wheels are not on an identical trajectory on a curved road. Therefore, the drive wheels should have different speeds for stable driving. Although the mechanical differential is mostly used to perform this task in conventional vehicles, the electronic differential or speed reference box is used for multi-motor electric vehicle systems as a virtual driver to transform the real driver decision to the reference speed for each wheel-motor. Figure 7 shows the scooter traveling distance on a curved road, $R_{w}, L_{w}, d_{w}$ and $\delta$ are the wheel radius, the distance between front and rear wheel, the distance between the driving wheels, and the steering angle, respectively (Hichem et al. 2019, Abdelafath et al. 2009, Nasri et al.2010, Nasri et al 2016). The distinction between traction wheel angular speeds is:

$$
\Delta \omega=\frac{d_{w} \cdot \tan \delta}{L_{w}} \omega^{*}
$$

The speed change is being changed when adding and subtracting to/from the average value of the wheels' reference speed $\left(\omega^{*}\right)$ to obtain each reference back angular speed $\left(\omega_{R}^{*}, \omega_{L}^{*}\right)$. In the Eq.19, $\delta$ is also used for determining the trajectory. When the value of $\delta$ is lower than $0(\delta<0)$, the scooter turns left. If $\delta$ is equal to $0(\delta=0)$, it goes straight. On the other situation, when the value of $\delta$ is higher than $0(\delta>0)$, it turns right. 


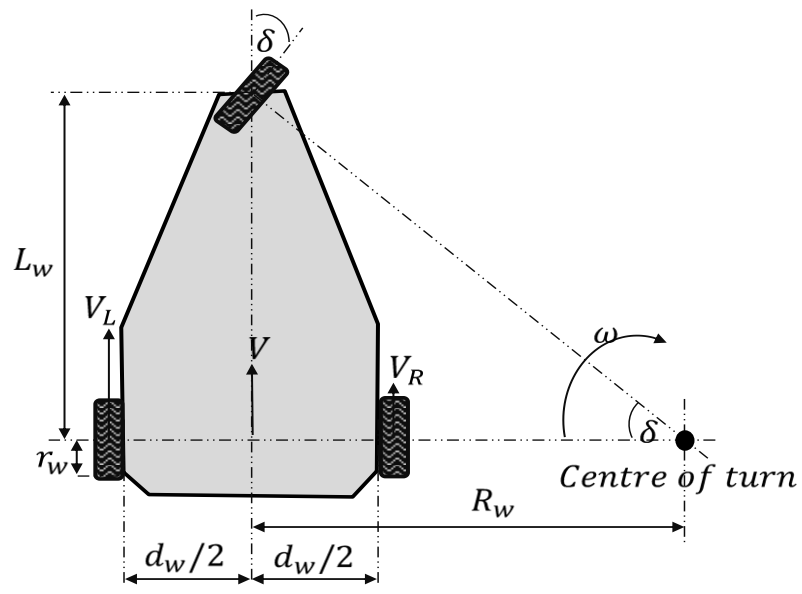

Fig. 7.The Geometry of the electric scooter moving on a curve.

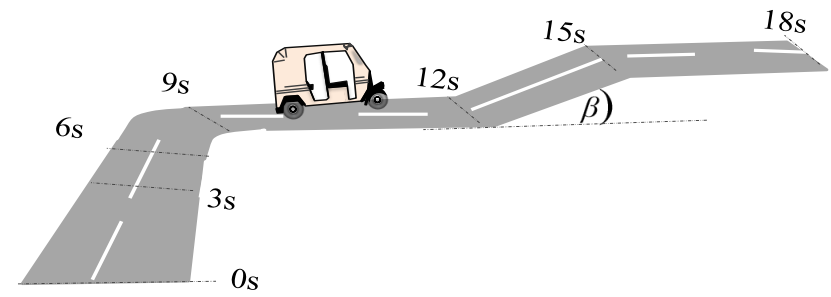

Fig. 8. The nature of the road trajectory

Table 1.

Studied road topology

\begin{tabular}{cccc}
\hline Time (s) & $\begin{array}{c}\text { Phase } \\
\text { number }\end{array}$ & Speed & Description \\
\hline$[0: 3]$ & 1 & 25 & straight road \\
{$[3: 6]$} & 2 & 45 & straight road \\
{$[6: 9]$} & 3 & 45 & right curved road \\
{$[9: 12]$} & 4 & 45 & straight road \\
{$[12: 15]$} & 5 & 45 & Slope road \\
{$[15: 18]$} & 6 & 45 & straight road \\
\hline
\end{tabular}

\subsection{Proposed road topology}

The proposed model is simulated under a variable reference speed and load having a direct relationship with the road topology. The reference speed of the scooter and the road topology is illustrated in Fig. 8 and Table 1. Figure 8 shows the nature of the road.

\section{Results and Discussions}

Simulations were performed based on the model developed and showed in Figure 6. In the first step of simulation in MATLAB software, the developed model of the electric scooter is simulated with the DTC control. In the second step, the model is simulated with using the DTC-SVM control strategy. Also, this model uses the electronic differential system (EDS) to compute the speed reference of each wheel. The road trajectory is well chosen to show the performance control of each model and the speed reference is well-chosen based on the commercialized parameter of the Asian electric scooter. Additionally, the vehicle resistive torque and the motor torque are chosen depending on this scooter too. The specified trajectory is divided into many stages as a straight, a slope or curved road. The analysis of the results is presented in the following sections.

\subsection{Linear speed of the driving wheel characteristics}

The dynamic performances of the electric scooter and the effect on the vehicle stability during driving are presented in this section. The reference speed is changed between 25 $\mathrm{Km} / \mathrm{h}$ to $45 \mathrm{Km} / \mathrm{h}$ and these speed references are chosen according to the vehicle reference parameters. The advantages of the EDS appear clearly in the curved road trajectory. The rising time, the overshooting and the settling time are good points to evaluate vehicle linear speed. Based on the first test of the linear speed, the SVM_DTC presents the best advantages when it is compared with the conventional control.

When the scooter travelled on a straight road, the wheels were initiated at the same speed reference, but when the vehicle entered a curved road, the speed of the wheels on the outer side of the curve became higher compared to the speed of the wheels on the inner side, as shown in Fig. 9. The control robustness is shown on the slope road (at time of 15 and 16 second respectively) when the vehicle speed is always maintaining at the reference.

Figure 10 shows the difference in the ability to control the speed between the SVM-DTC unit and the conventional controller. When the scooter enters a bend or a sloping road, it cause a rippling change in speed response between the internal and external wheels or under an increased resistive torque load.

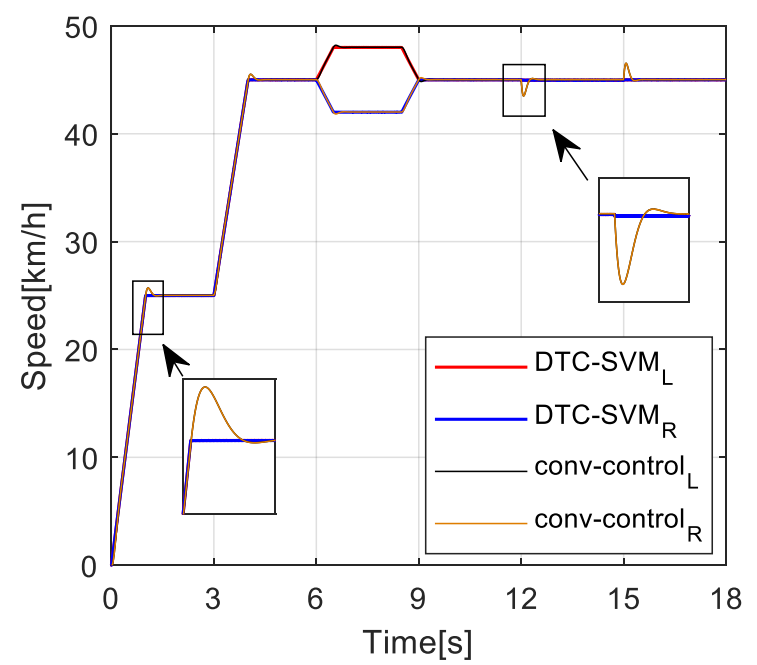

Fig. 9. Rear-wheel speeds using DTC, and DTC-SVM controller

Table 2

Performances of the conventional control and SVM-DTC for the speed response

\begin{tabular}{cccc}
\hline Controller & $\begin{array}{c}\text { rise time } \\
{[\mathrm{s}]}\end{array}$ & $\begin{array}{c}\text { settling } \\
\text { time }[\mathrm{s}]\end{array}$ & $\begin{array}{c}\text { overshooting } \\
{[\%]}\end{array}$ \\
\hline $\begin{array}{c}\text { Conventional } \\
\text { controller(DTC) } \\
\text { SVM-DTC }\end{array}$ & 0.2416 & 0.4376 & 4.111 \\
\hline
\end{tabular}


Table 2 explains the difference between the both applied controllers (conventional and SVM-DTC). The overshooting is less reduced in the SVM-DTC compared with the other controller. It presents the ratio of $(0.011 / 4.111)$ by means that the overshooting is reduced by 373 times compared to the classical control. When the rising time presents the ratio of $(0.1131 / 0.2416)$ by means that the SVM-DTC has very fast response compared with the other controller. Also, in the settling time level, the proposed controller presents only $(0.15115 \mathrm{Sec})$ when the classical control present settling time of 0.4376 seconds. The presented analysis about DTC-SVM control show that the speed performance is sufficient and suitable for the future studies related with the usage of SVM-DTC in the small electric scooter for smart traffic operations.

\subsection{Scooter resistive torque performances}

In this section, the impact of the mechanical load on the scooter motion characteristics is presented. In the first stage, the scooter starts up with a speed of $25 \mathrm{Km} / \mathrm{h}$ and the vehicle resistive torque is applied near to $29 \mathrm{Nm}$. In the second stage, the scooter is moved at a speed of $45 \mathrm{~km} / \mathrm{h}$ and the resistor torque became approximately $69 \mathrm{Nm}$. When the vehicle has a speed ratio of $(45 / 25)$ by means that the speed change of $180 \%$ and the mechanical load is presented by torque ratio of (69/29) by means change of 2.37 times in the global resistive torque. In another test, the resistive torque reached the value of $140 \mathrm{Nm}$ due to the motion on slope road effect. It causes an important development increase in resistive load that the global resistive torque took the value of 5 times compared with the straight road resistive torque.

Figure 16 shows a comparison between the SVM_DTC and the classic DTC on circular shape. The electromagnetic torque behavior (Fig.13) gives a good idea about the estimated effort demand for each motor (right of left) during the driving operations. At the current level, the in-wheel motor demand is computed according to the driver action and the electronic differential demand (Fig.14). The Back Electromotive Force (BEMF) has the same trajectory of the current demand by means that the BEMF has a direct relationship with the current as it's illustrated in the Eq.14 and Eq.15, and as is shown in Fig.14and Fig.15, respectively.

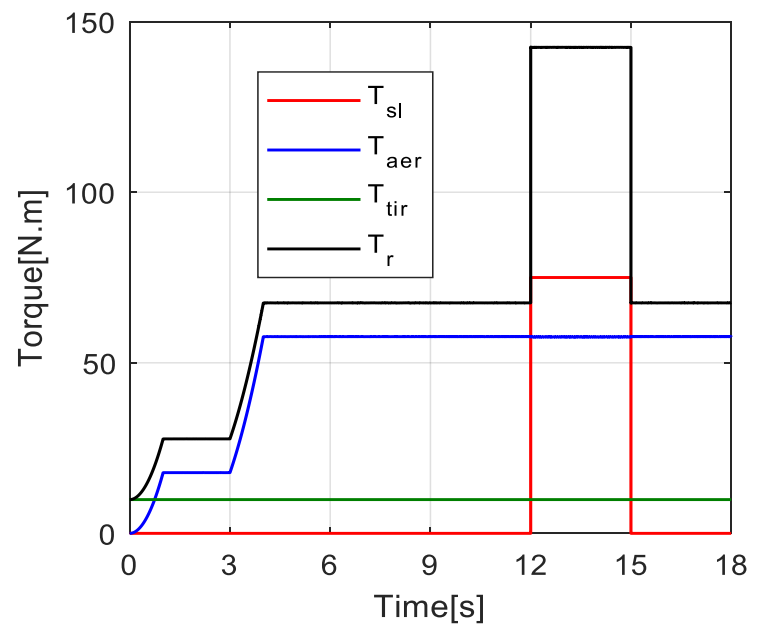

Fig. 10. The resistive torques acting on scooter motion

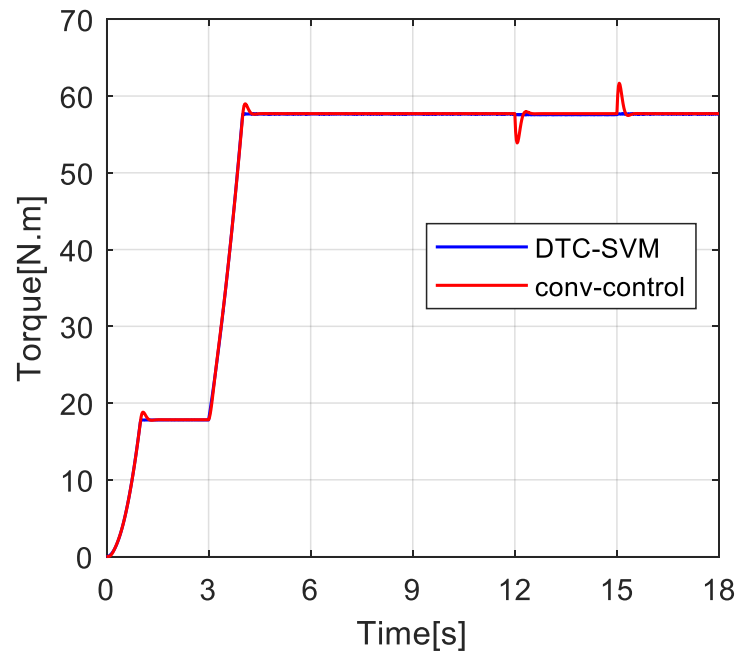

Fig. 11. Aerodynamic torque for DTC and DTC-SVM cases

\subsection{Scooter torque control (SVM_DTC) performances}

When the SVM-DTC is applied, the propulsion system provides a relatively lower dynamic torque comparing with the conventional torque control demand during its application, because the front-facing surface used to reach the reference speed is reduced, and the aerodynamic torque is optimized by means that: (the torque demand using the proposed control is upgraded during the driving), the torque ripple is decreased and the torque control maintain the reference in an easy way, the power, the current demand and the stator flux are used economically compared with other controllers.

According to the Table 3, the aerodynamic torque is reduced in DTC-SVM control compared with the DTC during all the tests (at 1.08-4.08 to 12.08-15.08 seconds). The aerodynamic torque present the linear speed picture of electric vehicle, it shows the uses of the vehicle frontal area in a different moment.

\subsection{The scooter driving force, and motor torque analysis}

As a geometric format it's observed that the flow in the stator using SVM-DTC have a precise circular shape compared to the shape obtained by using the conventional controller. Although the torque is changed, it does not affect the stator flow.

Table 3.

The values of the aerodynamic torque and the scooter resistive torque in different phases.

\begin{tabular}{ccccc}
\hline $\begin{array}{c}\text { Time } \\
{[\mathrm{s}]}\end{array}$ & $\begin{array}{r}\text { Aerodynamic torque } \\
{[\mathrm{N} . \mathrm{m}]}\end{array}$ & \multicolumn{2}{c}{$\begin{array}{c}\text { Vehicle resistive torque } \\
\text { Tr }[\mathrm{N} . \mathrm{m}]\end{array}$} \\
\cline { 2 - 5 } & $\begin{array}{c}\text { Conventional } \\
\text { control(DTC) }\end{array}$ & $\begin{array}{c}\text { SVM- } \\
\text { DTC }\end{array}$ & $\begin{array}{c}\text { Conventional } \\
\text { control(DTC) }\end{array}$ & $\begin{array}{c}\text { SVM- } \\
\text { DTC }\end{array}$ \\
\hline 1.08 & 18.84 & 17.8 & 28.71 & 27.7 \\
4.08 & 59 & 57.66 & 68.9 & 67.56 \\
12.08 & 53.88 & 57.66 & 138.8 & 142.5 \\
15.08 & 61.67 & 57.66 & 75.6 & 67.56 \\
\hline
\end{tabular}




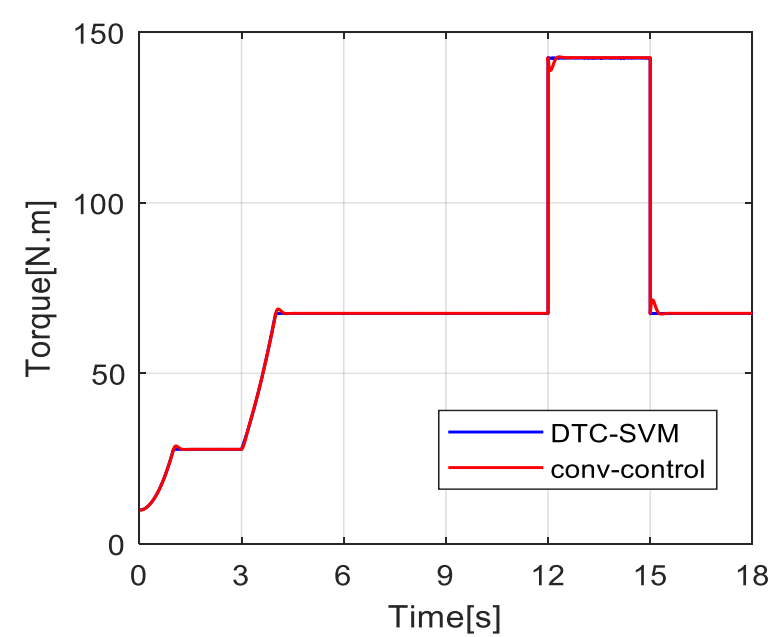

Fig. 12. Scooter global resistive torques for DTC and DTC-SVM cases

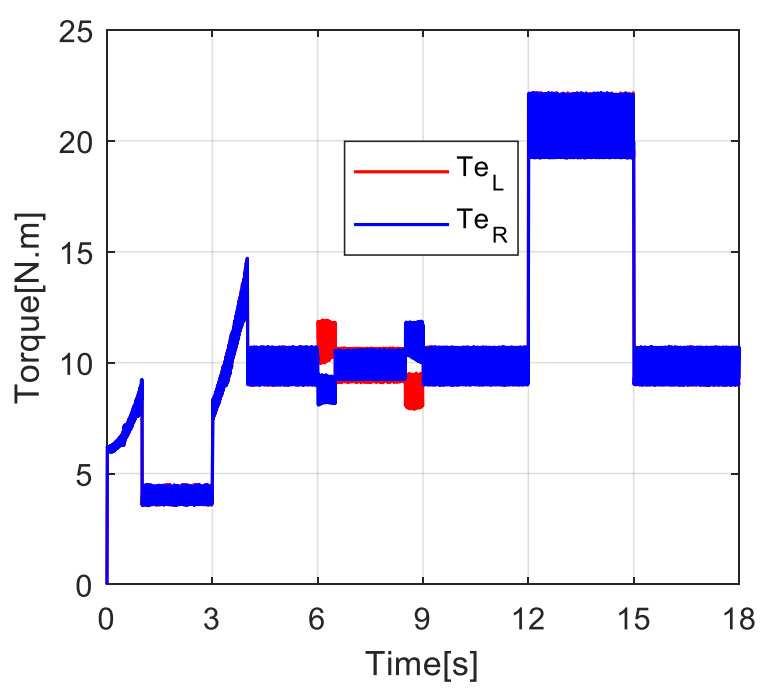

Fig. 13. Electromagnetic torques for driving wheels

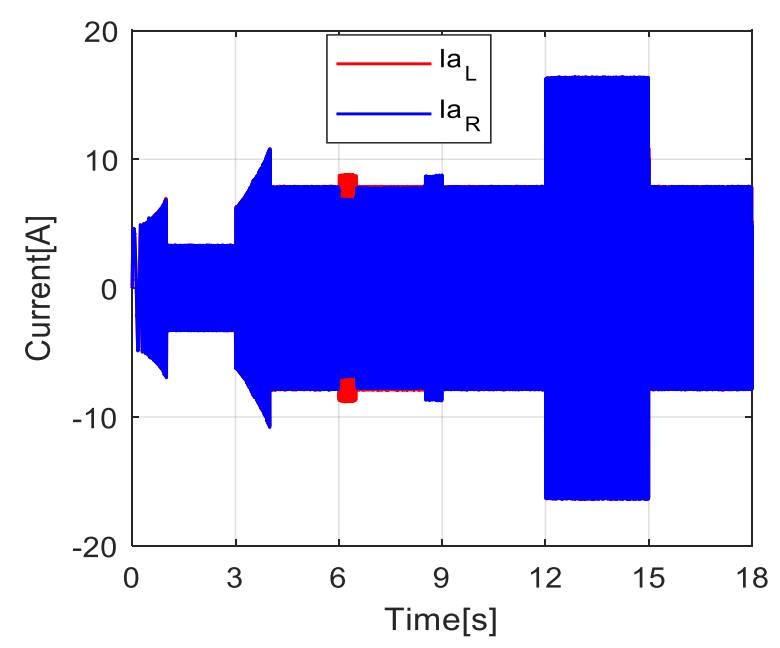

Fig. 14. The electric current of phase a.

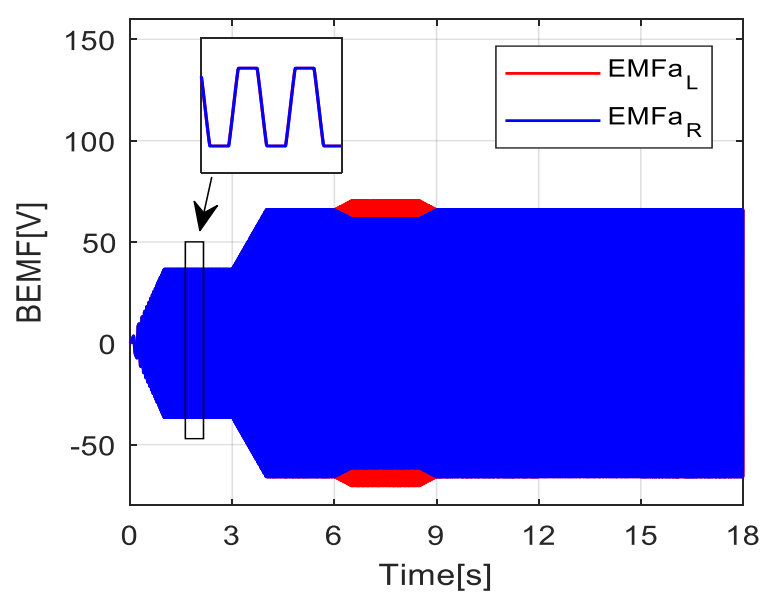

Fig. 15. Phase A: Back Electromotive Force BEMF of for right and left wheels.
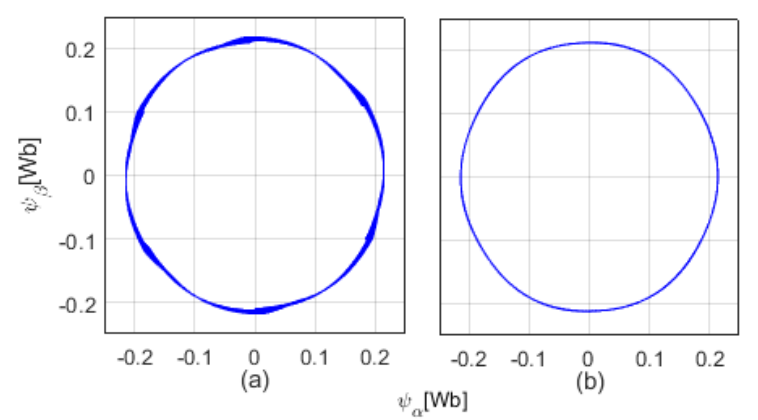

Fig. 16. Stator flux: (a) Conventional control (DTC). (b) SVMDTC.

4.3. The Scooter driving motor power electronics, and THD of driving motor analysis

This part describes the THD rate-indices development of the driving-wheel for both of DTC, and SVM-DTC control. The stator flux ripples of the electromagnetic torque effected the Total Harmonic Distortion (THD). To reduce these harmonics, the stator flux and the electromagnetic torque must be regulated. The SVM-DTC provide better THD performances than the conventional controller, the percentage of THD is only $6.16 \%$ in the SVM-DTC when this value is more than $30 \%$ for the conventional control. Figure 17 and 18 is presented to compare the THD behaviors of two different controllers. They show the harmonic analysis of stator current. The THD of the currents by the SVM-DTC control is considerably reduced.

\subsection{The battery as power source response:}

In this section, the Battery State of Charge (SOC) variation, and the battery power demand, and the BuckBoost output voltage variation are presented. In fact, it appeared clear the converter's ability to raise the battery voltage and maintaining it at the note value, to correct the dc-dc converter out-put it's important to the use BuckBoost in closed-loop assessment using the ProportionalIntegral, regardless of how much change the output voltage of the battery (Fig.20) with the Buck-Boost output voltage in different situations. 

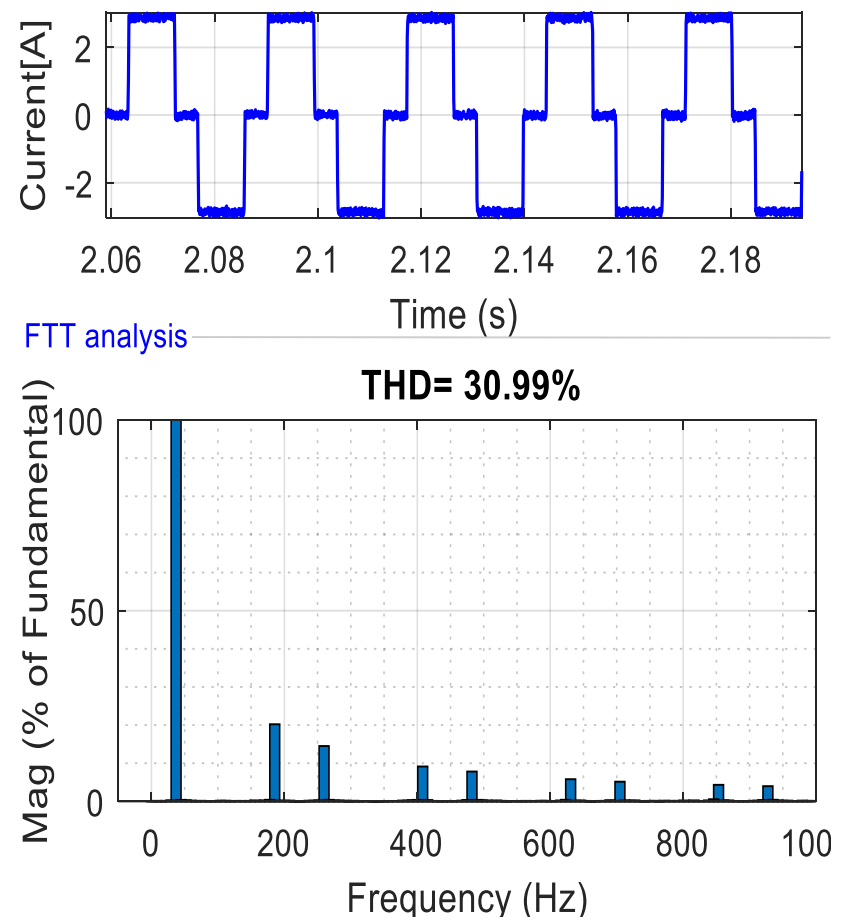

Fig. 17. Harmonic analysis of stator current for one driving wheel using DTC control.
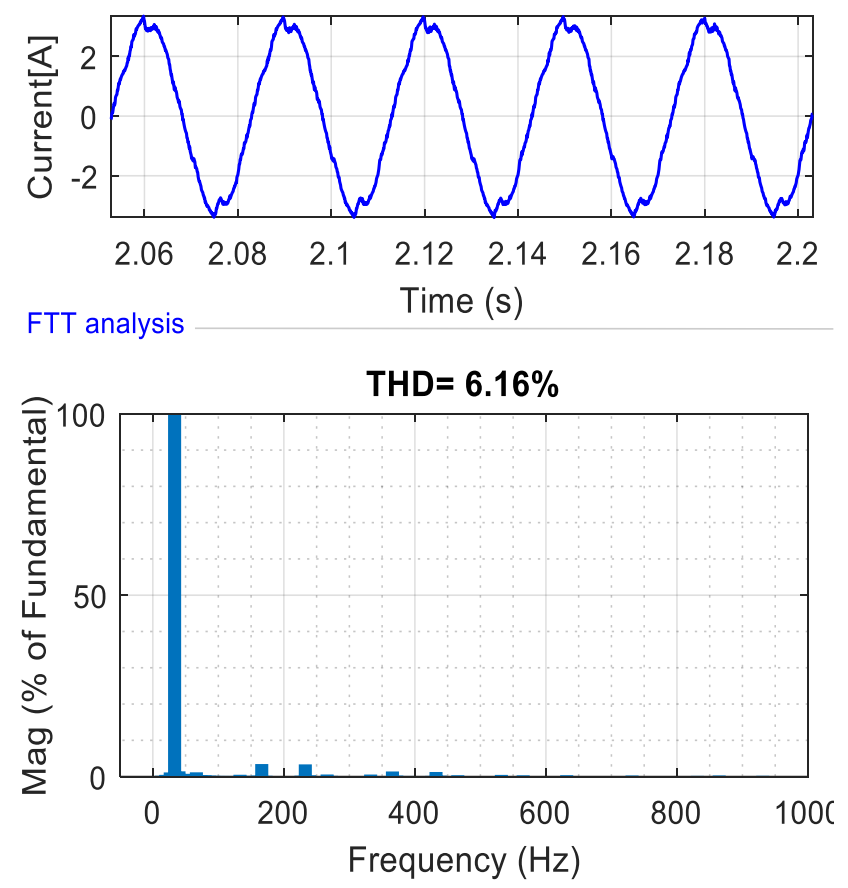

Fig. 18. Harmonic analysis of stator current for one driving wheel using SVM-DTC technique.

Figure 19 presents the battery output voltage. The battery current increases in the acceleration case (speed change from 25 to $45 \mathrm{Km} / \mathrm{h}$ ), and in slope road condition, that cause a rise in the use of power and a drop in the state of charge. Figure 23 illustrates the SOC of the electric scooter under different road/speed conditions, for the same road trajectory. The SOC performance of SVM_DTC is better than the DTC case.
Figure 21 shows the battery current in SVM-DTC and DTC case and the current consumption of SVM-DTC less than the conventional controller. It means that the usage of this controller makes an economic consumption of energy is better than other method. Figure 22 shows the battery power in different cases, and the efficiency of the proposed SVM-DTC control compared with the conventional method. It shows that the proposed method optimize the power consumption and give good economic power management for our electrical traction system.

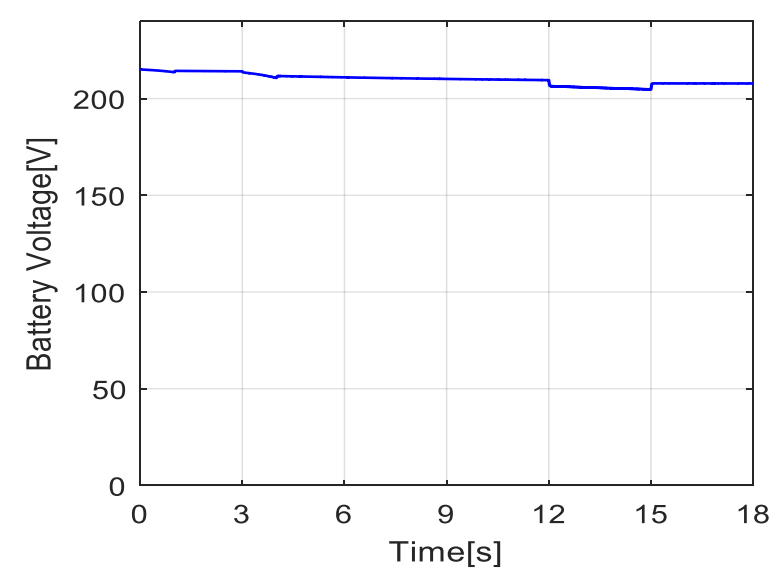

Fig. 19. The output voltage of the battery

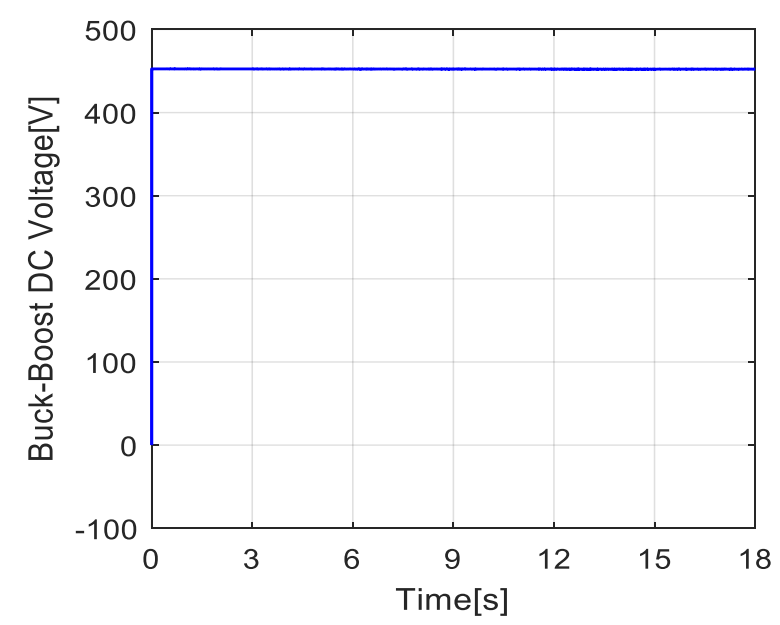

Fig. 20. The output voltage of the buck-boost converter

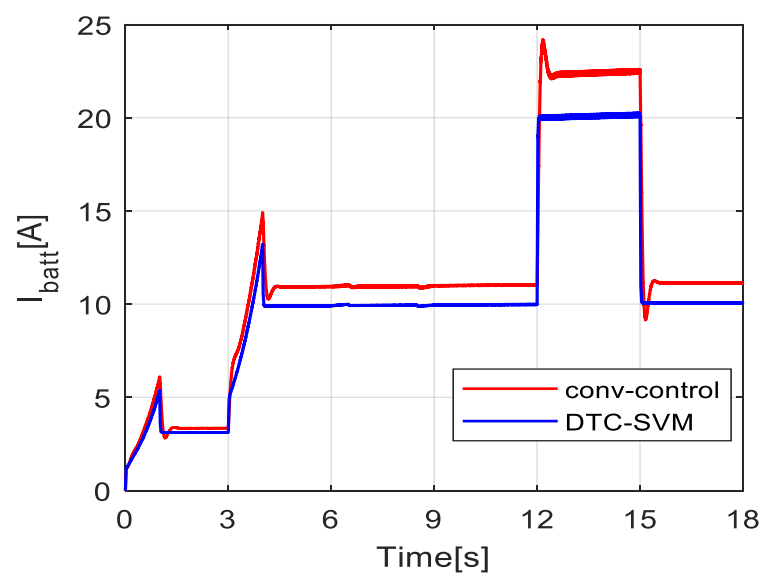

Fig. 21. The battery current in different cases (DTC and DTCSVM) 


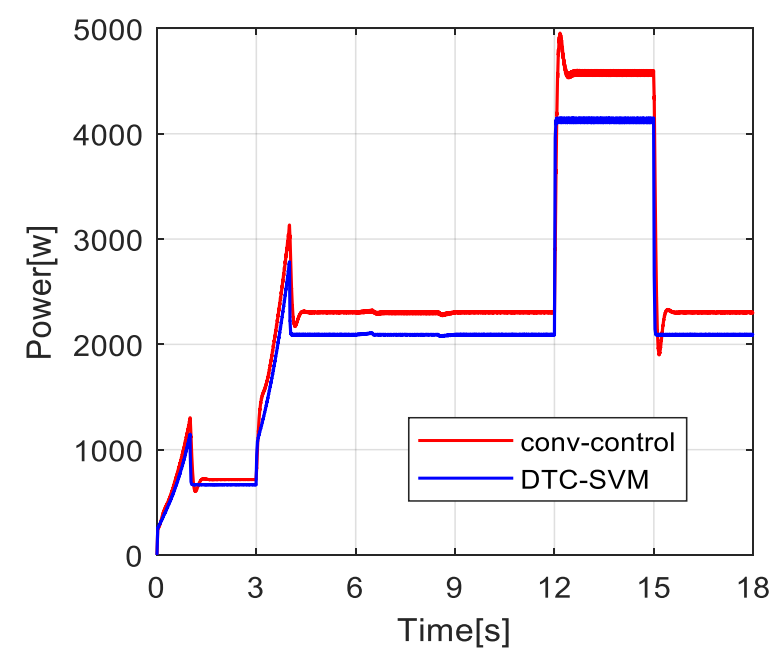

Fig. 22. The battery power in different cases.

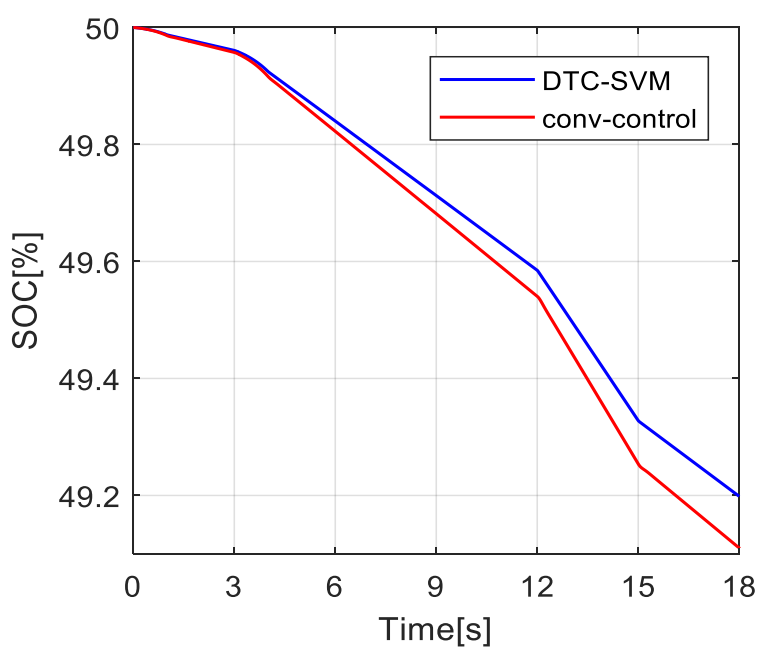

Fig. 23. The SOC variation using the DTC-SVM, and DTC Controller (conventional control) (\%).

Table 4

Variation of the battery current, the battery power, and SOC in a different trajectory

\begin{tabular}{ccccccc}
\hline \multirow{2}{*}{ Time [s] } & \multicolumn{2}{c}{ Battery current [A] } & \multicolumn{2}{c}{ Battery Power [Kw] } & \multicolumn{2}{c}{ SOC [\%] } \\
\cline { 2 - 7 } & $\begin{array}{c}\text { Conventional } \\
\text { control (DTC) }\end{array}$ & $\begin{array}{c}\text { SVM- } \\
\text { DTC }\end{array}$ & $\begin{array}{c}\text { Conventional } \\
\text { control (DTC) }\end{array}$ & $\begin{array}{c}\text { SVM- } \\
\text { DTC }\end{array}$ & $\begin{array}{l}\text { Conventional } \\
\text { control(DTC) }\end{array}$ & SVM-DTC \\
\hline 0 & 0 & 0 & 0 & 0 & 50.000 & 50.000 \\
1 & 6.1 & 5.4 & 1300 & 1150 & 49.980 & 49.990 \\
4 & 14.9 & 13.2 & 3100 & 2800 & 49.92 & 49.93 \\
12 & 24 & 20 & 4900 & 4100 & 49.54 & 49.58 \\
15 & 9.2 & 10.1 & 1900 & 2100 & 49.25 & 49.33 \\
18 & 11.1 & 10.1 & 2300 & 2100 & 49.11 & 49.2 \\
\hline
\end{tabular}

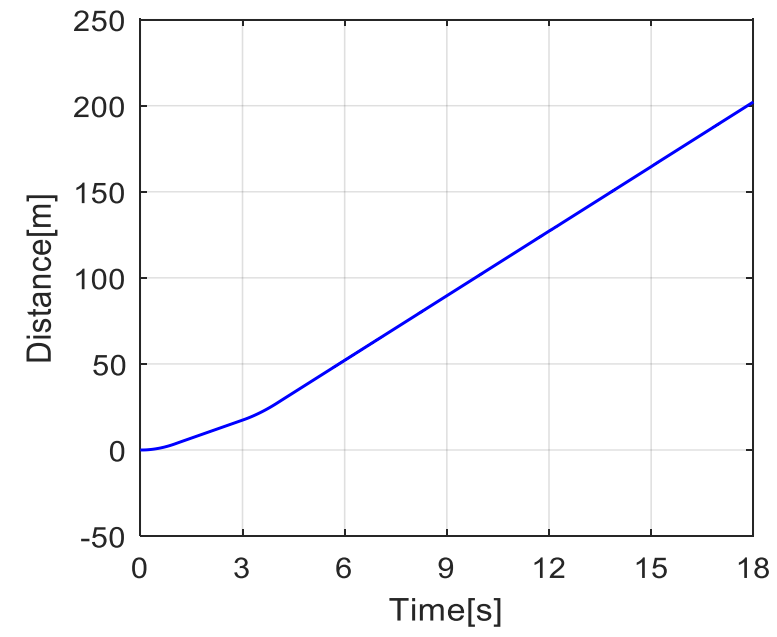

Fig. 24. The scooter traveled distances

The travelled distance by the electric scooter in time is shown in Fig. 24. This scooter crossed approximately 200 meters in 18 seconds by means that this scooter travels 666 meters in one minute with little variation of battery SOC.

\section{Conclusion}

This paper presents a three-wheel electric scooter simulation used for urban transportation. This small vehicle is simply a traction system composed of two BLDC motors for propulsion that propel the rear driving wheels. Each motor was independently controlled by the DTC, and SVM-DTC respectively, where it takes the reference speed for each motor from the electronic differential system. The prototype was simulated at different speeds and torques in different conditions depending on the road topology. According to de developed model, the electronic differential system gives smart action of the electric scooter.

From the simulations, the results clearly show the performances of the controller. The SVM-DTC provides rapid response, and improved the total harmonic distortion of the stator currents due to it robustness. Thus, fewer problems for the motor (overheating, mechanical vibration, aging, etc.) and less energy consumption can appear. In other hand, it permits an economical realization on battery current and power management during all trajectories and gives good dynamic performances for this electric scooter such as stability improvement. This SVM-DTC method presents a good performance for an urban electric scooter used for smart transportation. 


\section{Acknowledgements}

This work is included in the PHD thesis of Mr. Chergui Hichem and this paper is realized thanks to the SGRE laboratory. Through this work, I would like to thank the general management of scientific research development of DGRST for their role in developing scientific researches in Algeria, and their support for young researchers.

\section{References}

Abdelfatah, N., \&Brahim, G. (2011). The slopped road angle effect on lithium ions battery behavior for the next future commercialized electric vehicle. Journal of Electrical and Electronics Engineering, 4(2), 5.

Abdelfatah N, Abdeldjabar H, Ismail K. B, Samir. H, Pièrre S. (2008). Two Wheel Speed Robust Sliding Mode Control for Electric Vehicle Drive, Serbian Journal of Electrical Engineering, SJEE, 5(2), 2008, 199-216.

Abdelfatah N, Abdeldjabar H, Ismail K. B, Samir. H, Pièrre. (2009). Fuzzy-Sliding Mode speed control for electric vehicle drive, Korean Journal of Electrical Engineering Technology, JEET,4(4), 2009, 499-509.

Andreasen, S. J., Ashworth, L., Remon, I. N. M., \&Kær, S. K. (2008). Directly connected series coupled HTPEM fuel cell stacks to a Li-ion battery DC bus for a fuel cell electrical vehicle. international journal of hydrogen energy, 33(23), 7137-7145.

Bertoluzzo, M., \&Buja, G. (2011). Development of electric propulsion systems for light electric vehicles. IEEE Transactions on Industrial Informatics, 7(3), 428-435.

Boumediene, S., Abdelfatah, N., Hamza, T., \&Hicham, C. (2020, May). Power Supply Multisource Solar/Battery For Electric Scooter. In 020 1st International Conference on Communications, Control Systems and Signal Processing (CCSSP) (pp. 518-522). IEEE.

Caricchi, F., Del Ferraro, L., Capponi, F. G., Honorati, O., \&Santini, E. (2003). Three-wheeled electric maxi-scooter for improved driving performances in large urban areas. In IEEE International Electric Machines and Drives Conference, 2003. IEMDC'03. (Vol. 3, pp. 1363-1368). IEEE.

Duesterhoeft, W. C., Schulz, M. W., \& Clarke, E. (1951). Determination of instantaneous currents and voltages by means of alpha, beta, and zero components. Transactions of the American Institute of Electrical Engineers, 70(2), 12481255 .

Han, X., Ouyang, M., Lu, L., Li, J., Zheng, Y., \& Li, Z. (2014). A comparative study of commercial lithium ion battery cycle life in electrical vehicle: Aging mechanism identification. Journal of Power Sources, 251, 38-54.

Hannan, M. A., Azidin, F. A., \& Mohamed, A. (2012). Multisources model and control algorithm of an energy management system for light electric vehicles. Energy Conversion and Management, 62, 123-130.

Harušinec, J., Suchánek, A., Loulová, M., \&Kurčík, P. (2019). Design of a prototype frame of an electrically driven threewheel vehicle. In MATEC Web of Conferences (Vol. 254, p.
02014).

EDP

https://doi.org/10.1051/matecconf/201925402014

Hichem, C., Nasri, A., \&Kayisli, K. (2019). Fuzzy Logic Speed Control for Three-Wheel Electric Scooter. International Journal of Renewable Energy Research (IJRER), 9(3), 14431450.

Jensen, H. C. B., Schaltz, E., Koustrup, P. S., Andreasen, S. J., $\&$ Kær, S. K. (2012). Evaluation of fuel-cell range extender impact on hybrid electrical vehicle performance. IEEE Transactions on Vehicular Technology, 62(1), 50-60.

Jeong, S. G., Kwon, J. M., \& Kwon, B. H. (2019). High-efficiency bridgeless single-power-conversion battery charger for light electric vehicles. IEEE Transactions on Industrial Electronics, 66(1), 215-222.

Kommula, B. N., \& Kota, V. R. (2019). A Novel Single Input Double Output (SIDO) Converter for Torque Ripple Minimization in Solar Powered BLDC Motor. International Journal of Renewable Energy Development, 8(2), 161-168.

Lovley, I. J. B., Klingl, J. C., Groenhuyzen, M., \& Edlauer, K. "Three-wheeled electric scooter." U.S. Patent No. 9,592,876. 14 Mar. 2017.

Marzougui, H., Amari, M., Kadri, A., Bacha, F., \&Ghouili, J. (2017). Energy management of fuel cell/battery/ultracapacitor in electrical hybrid vehicle. International journal of hydrogen energy, 42(13), 8857-8869.

Nasri, A., Gasbaoui, B., \&Fayssal, B. M. (2016). Sliding mode control for four wheels electric vehicle drive. Procedia Technology, 22, 518-526.

Nasri. A, Gasbaoui. B (2017). Four Wheel Electric Vehicle Behavior Using Fuel Cell Supply Moving on Mountain Region Condition . International Journal on Electrical Engineering and informatics, IJEEI, 9(3),2017, 469-481.

Nasri, A., Hazzab, A., Bousserhane, I. K., Hadjeri, S., \&Sicard, P. (2010). Fuzzy logic speed control stability improvement of lightweight electric vehicle drive. Journal of Electrical Engineering \& Technology, 5(1), 129-139.

Pellegrino, G., Armando, E., \&Guglielmi, P. (2009). An integral battery charger with power factor correction for electric scooter. IEEE transactions on power electronics, 25(3), 751759 .

Pizzi, L. (2012). U.S. Patent Application No. 29/374,203.

Saxena, S., Gopal, A., \&Phadke, A. (2014). Electrical consumption of two-, three-and four-wheel light-duty electric vehicles in India. Applied energy, 115, 582-590.

Sindha, J., Chakraborty, B., \&Chakravarty, D. (2015, August). Rigid body modeling of three wheel vehicle to determine the dynamic stability-A practical approach. In 2015 IEEE international transportation electrification conference (ITEC) (pp. 1-8). IEEE.https://doi.org/10.1109/ITECIndia.2015.7386889

Tahri, F., Tahri, A., AlRadadi, E. A., \&Draou, A. (2007), September). Analysis and control of advanced static VAR compensator based on the theory of the instantaneous reactive power. In 2007 International Aegean Conference on Electrical Machines and Power Electronics, Bodrum, 2007, pp. 840-845, doi: 10.1109/ACEMP.2007.4510559. 